\title{
Response of the oxygen pulse during exercise in children with atrial repair for transposition of the great arteries
}

This article was published in the following Dove Press journal:

Research Reports in Clinical Cardiology

29 November 2012

Number of times this article has been viewed

\author{
Roselien Buys ${ }^{1,2, *}$ \\ Kimberly Dockx ${ }^{1, *}$ \\ Marc Gewillig ${ }^{3}$ \\ Tony Reybrouck ${ }^{1,2}$ \\ 'Department of Rehabilitation \\ Sciences, ${ }^{2}$ Department of \\ Cardiovascular Rehabilitation, \\ University of Leuven, Leuven, Belgium; \\ ${ }^{3}$ Department of Pediatric Cardiology, \\ University Hospital Gasthuisberg, \\ Leuven, Belgium \\ *These authors contributed equally to \\ this paper
}

Background: The oxygen pulse equals stroke volume times arterial-venous oxygen difference and is calculated by dividing oxygen uptake $\left(\mathrm{VO}_{2}\right)$ by heart rate $(\mathrm{HR})$. In children with a Senning repair for the transposition of the great arteries (TGA), the response of both HR and $\mathrm{VO}_{2}$ to exercise is impaired. Our aim was to assess the oxygen pulse response during exercise in patients who underwent a Senning operation, comparing it with healthy controls.

Methods: Twenty-one children with a Senning repair (mean age $12.5 \pm 1.7$ years) and a control group of 31 healthy children (mean age $13.2 \pm 2.0$ years) performed a graded maximal exercise test on a treadmill, during which $\mathrm{HR}$ and $\mathrm{VO}_{2}$ were measured. Oxygen pulse was calculated by dividing $\mathrm{VO}_{2}$ by $\mathrm{HR}$. Right ventricular function was quantitatively assessed by cardiac ultrasound.

Results: Senning patients had a lower peak oxygen pulse than the control $(P=0.0024)$ $\left(8.45 \pm 1.90 \mathrm{~mL} \cdot\right.$ beats $^{-1}$ versus $11.7 \pm 3.93 \mathrm{~mL} \cdot$ beats $\left.^{-1}\right)$, as with the peak $\mathrm{VO}_{2}(P<0.001)(35.8$ $\pm 5.67 \mathrm{~mL} \cdot \mathrm{min}^{-1} \cdot \mathrm{kg}^{-1}$ versus $\left.46.6 \pm 8.02 \mathrm{~mL} \cdot \mathrm{min}^{-1} \cdot \mathrm{kg}^{-1}\right)$ and peak HR $\left(171 \pm 14\right.$ beats $\cdot \mathrm{min}^{-1}$ versus $188 \pm 11$ beats $\left.\cdot \min ^{-1}\right)$. During submaximal exercise, oxygen pulse and $\mathrm{VO}_{2}$ were also significantly lower in Senning patients when compared to the control group $(P=0.027)$. In seven Senning patients (33\%), the oxygen pulse did not increase any further after the first exercise levels. These patients had lower right ventricular function compared to the control group $(P=0.04)$.

Conclusion: Children with a Senning repair for TGA have a reduced peak $\mathrm{VO}_{2}$, peak HR, and peak oxygen pulse. Their oxygen pulse starts off at a lower level, reaches its plateau earlier, and is related to right ventricular function. This variable can be considered a complementary parameter to assess cardiovascular exercise performance.

Keywords: transposition of the great arteries, Senning repair, oxygen pulse, cardiopulmonary exercise testing

\section{Introduction}

Many studies have reported that patients with an atrial switch operation for transposition of the great arteries (TGA) have reduced exercise performance. ${ }^{1-5}$ Maximal oxygen uptake and the anaerobic threshold have been measured to assess this reduction. Chronotropic incompetence, impaired systemic ventricular function, impaired intraatrial conduit function, impaired lung function with ventilation/perfusion mismatch, peripheral deconditioning, and the inability to increase stroke volume have all been used to explain this decreased exercise capacity. ${ }^{4-7}$ However, since maximal exercise tests in children often depend on the children's motivation, complementary information should be obtained from exercise parameters during the different submaximal stages of the exercise test. ${ }^{8}$
Correspondence:Tony Reybrouck Department of Cardiovascular Rehabilitation, University Hospital Gasthuisberg, Herestraat 49, 3000 Leuven, Belgium

$\mathrm{Tel}+32 \mathrm{I} 6342$ I8I

Fax $+32 \quad 16342 \quad 184$

Email tony.reybrouck@uz.kuleuven.ac.be 
The oxygen pulse (oxygen uptake divided by heart rate) equals stroke volume multiplied by the arterial-venous oxygen difference. In healthy subjects, the oxygen pulse continuously increases during exercise (Wasserman's Principles of Exercise Testing and Interpretation: Including Pathophysiology and Clinical Applications). Furthermore, the oxygen pulse has been used as a surrogate for stroke volume during exercise and has been shown to correlate with stroke volume obtained by radionuclide testing during submaximal exercise. ${ }^{9-12}$ In light of this, studies have supported the value of the oxygen pulse as a marker of cardiac performance in patients with ischemic heart disease, mitral valve disease, congestive heart failure, and hypertension. ${ }^{12-15}$

The response of a child's oxygen pulse to exercise is assumed to be different from the response in adults. ${ }^{16}$ Due to a child's smaller heart and total blood volume, stroke volume is lower both at rest and during exercise. ${ }^{17}$ Compared to adults, children have a higher heart rate in response to submaximal exercise, and a higher arterial-mixed venous oxygen difference during submaximal exercise further increases a child's cardiac output. When the oxygen pulse is used as an indicative parameter for the evaluation of stroke volume during graded exercise, Jones and Campbell consider the arterial-mixed venous oxygen difference to remain fairly constant. ${ }^{18}$ And, although Bar-Or and Rowland have proposed that a child's oxygen pulse can indirectly measure the stroke volume, to our knowledge the relationship between a child's oxygen pulse and stroke volume during exercise has not been investigated. ${ }^{16}$ Furthermore, since both heart rate and the oxygen uptake response to exercise are impaired in patients after a Senning operation for TGA, the oxygen pulse might also be altered, becoming an interesting parameter to assess a child's cardiac response to exercise. This, too, has yet to be investigated in children. Therefore, the aim of this study was to investigate the oxygen pulse at different exercise intensities in children with a Senning repair, comparing the results with a healthy control group.

\section{Methods}

\section{Patients}

Twenty-one patients were randomly selected from a database of exercise tests performed between 2005 and 2011 at the University Hospital Gasthuisberg. Only patients who were born with a complete TGA and underwent a Senning operation were included in this study. Patients mentally or physically unable to participate were excluded. The study group consisted of 12 male and nine female patients between 10 and 16 years of age. Thirty-one healthy control subjects of comparable age were also examined. There were 21 male and 10 female participants. The local medical ethical committee approved the study protocol, and all patients and parents gave informed consent for the testing procedure.

\section{Exercise testing}

Both patients $(\mathrm{n}=21)$ and controls $(\mathrm{n}=31)$ performed a graded maximal exercise test on a treadmill, during which heart rate (HR) and gas exchange parameters were measured. The measurements took place in the morning. The treadmill speed was set at $5.6 \mathrm{~km} / \mathrm{h}$ with an inclination of $0 \%$. Every minute the inclination was increased by $2 \%$ until exhaustion (as defined by shortness of breath and/or fatigue in the legs) was reached. Exhaustion was reached within 5 to 12 minutes. The children were verbally encouraged to perform a true maximal effort. Support from the handrails in order to maintain balance was not allowed. Oxygen uptake and carbon dioxide output were measured on a breath-bybreath basis by a computerized system with fast-responding electronic gas analyzers (MedGraphics Ultima CPX, Medical Graphics Corporation, St Paul, MN). Inspiratory and expiratory flow was measured with a Pitot flow meter (VMM-110; Alpha Technologies, Akron, OH). The system was calibrated before each exercise test with a test gas of known composition. Heart rhythm was continuously monitored during exercise by the ECG monitor (Max Personal Exercise Testing, Marquette, WI), and a 12-lead electrocardiogram was recorded at one-minute intervals. Peak exercise performance was assessed by determining the peak oxygen uptake (peak $\mathrm{VO}_{2}$ ). Oxygen pulse was calculated by dividing $\mathrm{VO}_{2}$ by $\mathrm{HR}$. The Senning patients' pattern of the oxygen pulse during the first four stages of the graded exercise was compared with the control group.

\section{Echocardiography}

Experienced echocardiographers performed a routine transthoracic echocardiography in all the Senning patients, using standardized views either on an Acuson 128 (Interspec Apogee CX, ATL, Bothell, WA) or Interspec (Acuson 128 $\mathrm{XP}$, Siemens, Erlangen, Germany) apparatus. As is common practice, right ventricular contractility was qualitatively graded as normal (grade 1), mild (grade 2), moderate (grade 3 ), and severe (grade 4) in terms of dysfunction.

\section{Statistical analysis}

SAS $^{\circledR}$ Enterprise Guide ${ }^{\circledR}$ statistical software, version 4.2 for windows (SAS Institute Inc, Cary, NC, USA), was used for the analysis. Data were reported as means and standard deviations. 
Comparisons of means between patients and healthy controls were performed by the two-tailed $t$-test. A one-sided Wilcoxon signed-rank test was used for the comparison of right ventricular function between the groups. Repeated measures ANOVA was used for group analysis. The Spearman correlation coefficient was used for the evaluation of relationships between exercise measures and right ventricular function. The level of statistical significance was set at $P<0.05$.

\section{Results}

\section{Patient characteristics}

Patient characteristics are listed in Table 1. There was no significant difference between the groups. In five Senning patients, right ventricular function was normal, 12 patients showed a slightly reduced right ventricular function, and four patients had a moderately impaired right ventricular function, as assessed by echocardiography.

\section{Peak exercise measures}

All patients and control subjects reached peak respiratory exchange ratios greater than 1.05 , documenting evident exhaustion. Peak oxygen pulse ( $P=0.0024)$ was significantly lower in patients with a Senning repair, compared to the control group $\left(8.4 \pm 1.9 \mathrm{~mL} \cdot\right.$ beats $^{-1}$ versus $11.7 \pm 3.9 \mathrm{~mL} \cdot$ beats $\left.^{-1}\right)$. Peak $\mathrm{VO}_{2}$ and peak $\mathrm{VO}_{2} / \mathrm{kg}(P=0.0002)$ were significantly lower in patients with a Senning repair, compared to the control group $\left(35.80 \pm 5.67 \mathrm{~mL} \cdot \mathrm{min}^{-1} \cdot \mathrm{kg}^{-1}\right.$ versus $\left.46.60 \pm 8.02 \mathrm{~mL} \cdot \mathrm{min}^{-1} \cdot \mathrm{kg}^{-1}\right)$ (Table 2). Peak heart rate $(P=0.0003)$ was significantly lower in the Senning group, compared to the control group $\left(171 \pm 14\right.$ beats $\cdot \mathrm{min}^{-1}$ versus $188 \pm 11$ beats $\cdot \min ^{-1}$ ).

\section{Submaximal exercise measures}

In Figure 1, the oxygen pulse is shown during submaximal exercise. It increased both in patients and healthy controls during graded exercise at submaximal exercise levels $(P<0.0001)$. In the control group, a continuous increase in oxygen pulse was observed. However, in the group of children with a Senning repair, the oxygen pulse only increased during

Table I Patient characteristics

\begin{tabular}{llll}
\hline & $\begin{array}{l}\text { Senning } \\
(\mathbf{n}=\mathbf{2} \text { I) }\end{array}$ & $\begin{array}{l}\text { Control } \\
(\mathbf{n = 3})\end{array}$ & P-value \\
\hline $\begin{array}{lll}\text { Sex } \\
\text { Male }\end{array}$ & $12(57)$ & $21(68)$ & 0.45 \\
$\quad$ Female & $9(43)$ & $10(32)$ & \\
Age (years) & $12.5 \pm 1.7$ & $13.2 \pm 1.9$ & 0.23 \\
Weight $(\mathrm{kg})$ & $41 \pm 1 \mathrm{I}$ & $47 \pm 10$ & 0.05 \\
\hline
\end{tabular}

Note: All variables are expressed as number (percentage) or as means \pm standard deviation.
Table 2 Peak exercise performance variables

\begin{tabular}{lccc}
\hline & $\begin{array}{l}\text { Senning } \\
(\mathbf{n}=\mathbf{2 1})\end{array}$ & $\begin{array}{l}\text { Control } \\
(\mathbf{n}=\mathbf{3 I})\end{array}$ & P-value \\
\hline $\begin{array}{l}\text { Peak oxygen pulse } \\
(\mathrm{mL} \cdot \text { beats }\end{array}$ & $8.45 \pm 1.90$ & $1 \mathrm{I} .70 \pm 3.93$ & 0.0024 \\
$\begin{array}{l}\text { Peak VO } \\
\left(\mathrm{mL} \cdot \mathrm{min}^{-1}\right)\end{array}$ & $1443 \pm 338$ & $2190 \pm 663$ & $<0.000 \mathrm{I}$ \\
$\begin{array}{l}\text { Peak VO } \\
\left(\mathrm{mL} \cdot \mathrm{min}^{-1} \cdot \mathrm{kg}^{-1}\right)\end{array}$ & $35.80 \pm 5.67$ & $46.60 \pm 8.02$ & 0.0002 \\
$\begin{array}{l}\text { Peak heart rate } \\
\left.\text { (beats } \cdot \mathrm{min}^{-1}\right)\end{array}$ & $171 \pm 14$ & $188 \pm \mathrm{II}$ & 0.0003 \\
\hline
\end{tabular}

Note: All variables are expressed as means \pm standard deviation.

Abbreviation: $\mathrm{VO}_{2}$, oxygen uptake.

the first two minutes of exercise $(0 \%$ and $2 \%$ inclination); at higher intensities of exercise no further increase in oxygen pulse was found. In patients with a Senning repair, as opposed to the control group, significantly lower values were found during the first minute of exercise as well as during the next studied levels of graded exercise $(P=0.027)$.

When the oxygen pulse response was studied in every subject separately, seven Senning patients (33\%) could not increase their oxygen pulse after the first stages of exercise, or even showed a decrease in oxygen pulse during graded exercise. These patients had a significantly lower right ventricular function $(P=0.04)$.

Compared to the control group, patients with a Senning repair had significantly lower oxygen uptake levels during

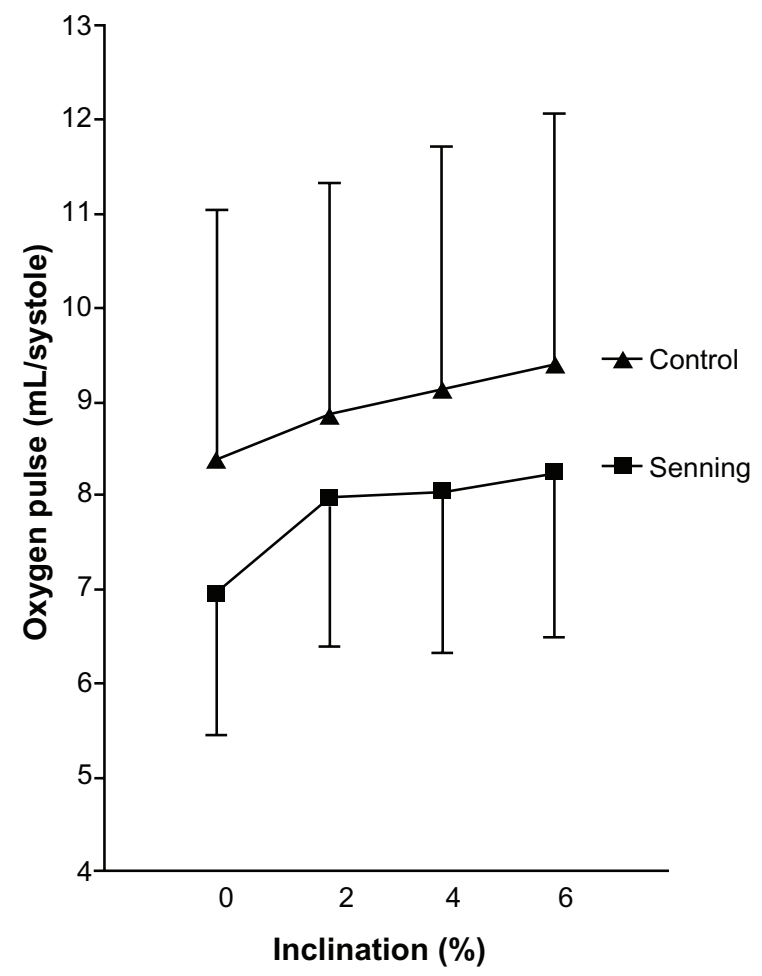

Figure I Response of the oxygen pulse during graded submaximal exercise. 


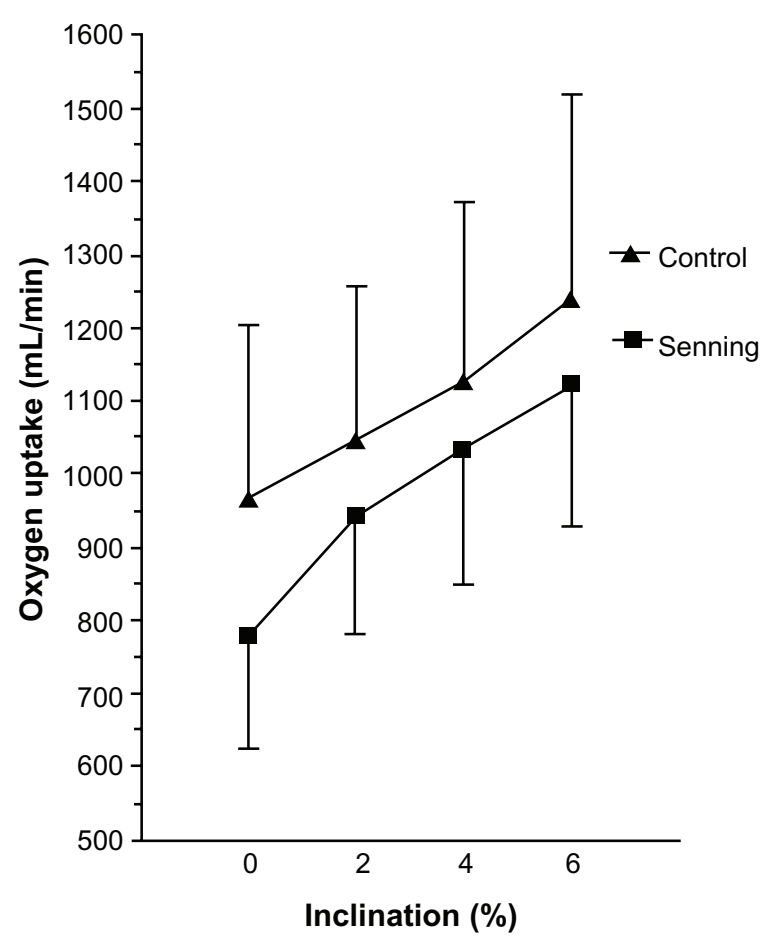

Figure 2 Response of the oxygen uptake during graded submaximal exercise.

submaximal exercise and throughout all levels of exercise (Figure 2).

\section{Discussion}

In patients with TGA after a Senning repair, we found a lower increase in oxygen pulse during graded submaximal exercise when compared to healthy controls. This was partly related to lower right ventricular function. Moreover, peak oxygen pulse, peak $\mathrm{VO}_{2}$, and peak HR were significantly reduced in patients with a Senning repair when compared to healthy subjects of comparable age and weight.

\section{Oxygen pulse}

We found significantly lower values for the oxygen pulse during graded exercise for Senning patients. If we assume that oxygen uptake is more reduced than $\mathrm{HR}$, then a reduced stroke volume could explain these lower values in the Senning group's oxygen pulses.

Unlike the healthy children, who showed a progressive increase in oxygen pulse during graded exercise, patients with a Senning repair did not further increase their oxygen pulse after the first levels of exercise. Our results suggest that, in patients with a Senning repair, the oxygen pulse seems to be partly determined by differences in contractility of the systemic right ventricle. Furthermore, a restricted blood flow through the atrial baffles during exercise and a higher than normal systemic vascular resistance during exercise might also contribute to an abnormal response of the oxygen pulse during exercise. ${ }^{19}$ As a result of the Senning operation, the disruption of adrenergic nerve fibers, causing myocardial scarring and partial denervation, may also have influenced the heart rate response to exercise, leading to chronotropic incompetence. ${ }^{2,3}$ However, this did not seem to affect our findings at submaximal exercise levels.

We also found lower values for peak oxygen pulse in patients with a Senning repair than in the control group. Paul and Wessel reported similar results with exercise testing during a bicycle exercise in 38 children and adolescents with a Mustard repair for TGA, compared to 44 healthy controls. ${ }^{1}$ Their findings show a greater reduction in oxygen uptake than the reduction in heart rate, and consequently a significantly lower peak oxygen pulse in Mustard patients compared to healthy controls. Likewise, Sterrett et al recently described a reduced oxygen pulse in adults with a Mustard or Senning repair, suggesting a diminished peak stroke volume. ${ }^{20}$

\section{Oxygen uptake}

Both at submaximal exercise levels and at peak exercise, Senning patients in our study had a significantly lower oxygen uptake than the controls. In agreement with the literature, our results show that peak oxygen uptake is impaired in children and adolescents with TGA. ${ }^{1,3,21}$ Right ventricular dysfunction, tricuspid regurgitation, impaired chronotropic response, and atrial arrhythmia are major factors limiting the exercise capacity. ${ }^{4-7}$ We previously documented a reduced oxygen uptake during submaximal exercise in this population, which we now reconfirm. ${ }^{8}$ Roest et al used cardiac magnetic resonance imaging to assess cardiovascular function during submaximal exercise, and they reported similar results in 27 patients, $23 \pm 2$ years after atrial correction of TGA. ${ }^{19}$ In their study, significantly lower oxygen uptake values were found during submaximal exercise for patients with TGA compared to a control group. Roest et al also found that the systemic right ventricular ejection fraction during exercise, and the percentage of change in right ventricular ejection fraction from rest to exercise, correlated significantly with peak oxygen uptake. Unfortunately, Roest et al did not investigate relationships with the oxygen pulse. In our study, we could not show a statistical relationship between right ventricular function and oxygen uptake.

\section{Heart rate}

In healthy subjects, a lower heart rate during submaximal exercise generally indicates a good or excellent aerobic 
exercise performance. A longer diastolic filling time and a higher stroke volume often accompany this lower heart rate. ${ }^{3}$ Patients with a Senning repair also show lower heart rates during submaximal exercise. Roest et al found a significantly lower increase in the right ventricular ejection fraction and the stroke volume during submaximal exercise in patients with a Senning repair. ${ }^{19}$ They attributed this to abnormalities in contractility of the systemic right ventricle, restricted flow through the atrial baffles during exercise, and a higher systemic vascular resistance during exercise. Therefore, the reduced heart rate, as measured in our study, might not be associated with excellent exercise capacity, longer filling time, and a higher stroke volume, but rather with abnormalities in contractility of the systemic right ventricle. Likewise, in our study, the peak heart rate was significantly reduced in patients with a Senning repair when compared to the control group. This chronotropic incompetence may also be an important factor contributing to the impaired peak oxygen uptake.

Although patients with a Senning repair for TGA have a lower exercise capacity than the healthy controls, they can still perform physical activities at a low or moderate intensity in daily life..$^{22,23}$

\section{Conclusion}

Children with a Senning repair for transposition of the great arteries have a substantially reduced oxygen pulse. During exercise, the oxygen pulse in Senning patients also shows a different pattern than the healthy controls; it starts off at a lower level, does not increase in a normal way during graded exercise, and seems to be related to right ventricular function. Consequently, the oxygen pulse can be considered a complementary parameter to assess cardiovascular exercise performance, in addition to oxygen uptake and heart rate.

\section{Disclosure}

The authors report no conflicts of interest in this work.

\section{References}

1. Paul MH, Wessel HU. Exercise studies in patients with transposition of the great arteries after atrial repair operations (Mustard/Senning): a review. Pediatr Cardiol. 1999;20(1):49-55.

2. Fredriksen PM, Veldtman G, Hechter S, et al. Aerobic capacity in adults with various congenital heart diseases. Am J Cardiol. 2001;87(3):310-314.

3. Reybrouck T, Vangesselen S, Gewillig M. Impaired chronotropic response to exercise in children with repaired cyanotic congenital heart disease. Acta Cardiol. 2009;64(6):723-727.

4. Diller GP, Dimopoulos K, Okonko D, et al. Exercise intolerance in adult congenital heart disease: comparative severity, correlates, and prognostic implication. Circulation. 2005;112(6):828-835.
5. Reybrouck T, Mertens L, Brown S, Eyskens B, Daenen W, Gewillig M. Long-term assessment and serial evaluation of cardiorespiratory exercise performance and cardiac function in patients with atrial switch operation for complete transposition. Cardiol Young. 2001;11(1):17-24.

6. Fredriksen PM, Pettersen E, Thaulow E. Declining aerobic capacity of patients with arterial and atrial switch procedures. Pediatr Cardiol. 2009;30(2):166-171.

7. Budts W, Scheurwegs C, Stevens A, Moons P, Van Deyk K, Vanhees L. The future of adult patients after Mustard or Senning repair for transposition of the great arteries. Int J Cardiol. 2006;113(2): 209-214.

8. Reybrouck T, Mertens L, Kalis N, et al. Dynamics of respiratory gas exchange during exercise after correction of congenital heart disease. J Appl Physiol. 1996;80(2):458-463.

9. Whipp BJ, Higgenbotham MB, Cobb FC. Estimating exercise stroke volume from asymptotic oxygen pulse in humans. J Appl Physiol. 1996;81(6):2674-2679.

10. Jones S, Elliott PM, Sharma S, McKenna WJ, Whipp BJ. Cardiopulmonary responses to exercise in patients with hypertrophic cardiomyopathy. Heart. 1998;80(1):60-67.

11. Hsi WL, Wong PL, Lai JS. Submaximal oxygen pulse divided by body weight during incremental exercise test. Am J Phys Med Rehabil. 1997;76(4):297-303.

12. Klainman E, Fink G, Lebzelter J, et al. The relationship between left ventricular function assessed by multigated radionuclide test and cardiopulmonary exercise test in patients with ischemic heart disease. Chest. 2002;121(3):841-845.

13. Klainman E, Fink G, Lebzelter J, Zafrir N. Assessment of functional results after percutaneous transluminal coronary angioplasty by cardiopulmonary exercise test. Cardiology. 1998;89(4):257-262.

14. Nery LE, Wasserman K, French W, Oren A, Davis JA. Contrasting cardiovascular and respiratory responses to exercise in mitral valve and chronic obstructive pulmonary diseases. Chest. 1983;83(3): 446-453.

15. Lim JG, McAveney TJ, Fleg JL, et al. Oxygen pulse during exercise is related to resting systolic and diastolic left ventricular function in older persons with mild hypertension. Am Heart J. 2005;150(5): 941-946.

16. Bar-Or O, Rowland TW. Cardiovascular heart diseases. In: Robertson LD, editor. Pediatric Exercise Medicine: From Physiologic Principles to Health Care Application. Champaign, USA: Human Kinetics; 2004:177-213.

17. Wilmore JH, Costill DL. Physiology of Sport and Exercise. Champaign, IL: Human Kinetics; 2004.

18. Jones NL, Campbell EJM. Clinical Exercise Testing. 2nd ed. Philadelphia: WB Saunders; 1982.

19. Roest AA, Lamb HJ, van der Wall EE, et al. Cardiovascular response to physical exercise in adult patients after atrial correction for transposition of the great arteries assessed with magnetic resonance imaging. Heart. 2004;90(6):678-684.

20. Sterrett LE, Ebenroth ES, Montgomery GS, Schamberger MS, Hurwitz RA. Pulmonary limitation to exercise after repair of D-transposition of the great vessels: atrial baffle versus arterial switch. Pediatr Cardiol. 2011;32(7):910-916.

21. Martins P, Castela E. Transposition of the great arteries. Orphanet $J$ Rare Dis. 2008;3:27.

22. Hirth A, Reybrouck T, Bjarnason-Wehrens B, Lawrenz W, Hoffmann A. Recommendations for participation in competitive and leisure sports in patients with congenital heart disease: a consensus document. Eur $J$ Cardiovasc Prev Rehabil. 2006;13(3):293-299.

23. Takken T, Giardini A, Reybrouck T, et al. Recommendations for physical activity, recreation sport, and exercise training in paediatric patients with congenital heart disease: a report from the Exercise, Basic and Translational Research Section of the European Association of Cardiovascular Prevention and Rehabilitation, the European Congenital Heart and Lung Exercise Group, and the Association for European Paediatric Cardiology. Epub August 22, 2011. 


\section{Publish your work in this journal}

Research Reports in Clinical Cardiology is an international, peerreviewed, open access journal publishing original research, reports, editorials, reviews and commentaries on all areas of cardiology in the clinic and laboratory. The manuscript management system is completely online and includes a very quick and fair peer-review system.

Visit http://www.dovepress.com/testimonials.php to read real quotes from published authors.

Submit your manuscript here: http://www.dovepress.com/research-reports-in-clinical-cardiology-journal 